\title{
Feeding Regimen
}

National Cancer Institute

\section{Source}

National Cancer Institute. Feeding Regimen. NCI Thesaurus. Code C90383.

A plan that specifies a diet, amount and schedule of nutritional intake. 